\title{
Commentary: The end of the beginning: The evolving role of mechanical circulatory support in children with heart failure
}

\author{
Ryan R. Davies, MD
}

\footnotetext{
From the Department of Cardiovascular and Thoracic Surgery, UT Southwestern Medical Center and Children's Health, Dallas, Tex.

Disclosures: Author has nothing to disclose with regard to commercial support.

Received for publication April 14, 2019; revisions received April 14, 2019; accepted for publication April 15, 2019; available ahead of print June 27, 2019.

Address for reprints: Ryan R. Davies, MD, 1935 Medical District Dr, MC B3.410, Dallas, TX (E-mail: ryan. davies@utsouthwestern.edu).

J Thorac Cardiovasc Surg 2019;158:1444-5

$0022-5223 / \$ 36.00$

Copyright (c) 2019 by The American Association for Thoracic Surgery

https://doi.org/10.1016/j.jtcvs.2019.04.085
}

The rapid evolution in mechanical circulatory support technology has resulted in dramatic improvements in the treatment of heart failure in adults. Early survival after ventricular assist device (VAD) implantation is similarin selected groups-to that after transplantation. ${ }^{1}$ There is an increasing recognition that, especially in the context of the dramatic imbalance between the prevalence of heart failure in adults and the availability of donor allografts, we are rapidly approaching the point at which for many adult patients, long-term VAD support will offer better outcomes than transplantation. ${ }^{2}$ To what degree these considerations apply in children is less certain.

The expert opinion from Dr Adachi ${ }^{3}$ in this issue of the Journal suggests that we may be closer to permanent mechanical support in children than we think. Although Dr Adachi $^{3}$ is correct that outcomes have steadily improved and technologic advances are certain to continue to lower the morbidity and mortality associated with VAD use, we are still far from the point at which VADs provide an alternative preferable to transplant in most pediatric patients. At 6 months, survival after intracorporeal, continuous-flow VAD implantation is only $86.5 \%$ in children and $93 \%$ in adults. ${ }^{4}$ This is not dissimilar to post-transplant survival, but long-term results in both adults and children demonstrate a constant ongoing hazard of morbidity and mortality on VAD support. In adults, median survival is less than 5 years. ${ }^{5}$ It will be some time before VADs can approach the long-term survival in children after transplantation.

However, Dr Adachi's ${ }^{3}$ excellent discussion of the relative advantages and disadvantages of VADs and transplants is directly relevant to the current management of children with heart failure. The approach used by Dr Adachi ${ }^{3}$ at Texas Children's Hospital of delaying transplantation after VAD implantation has the potential to improve both candidacy for transplantation and outcomes following, but more important the potential for recovery of native cardiac function and complete avoidance of transplant. Unfortunately,

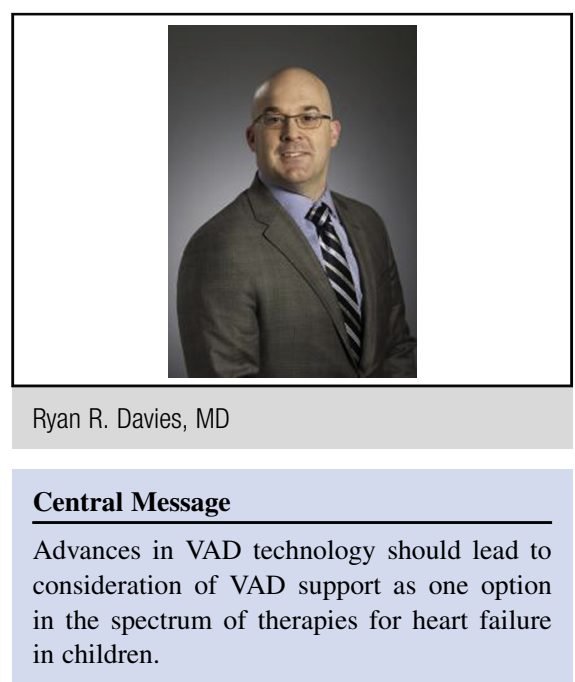

See Article page 1438.

there remains little data to answer the critical questions raised by that approach: What period of time should we wait for recovery? What should our indications be for listing and transplantation? At what point does the potential morbidity and mortality of a VAD outweigh the benefits of waiting? These are the questions we should ask of our data moving forward, as well as the questions we should ask for each child we are treating.

Until we have hard data to guide us, we can use the principles that Dr Adachi ${ }^{3}$ lays out. For some patients, the manageability of a VAD will provide distinct advantages over transplantation. For others the adaptability or hemocompatibility of transplant may be more critical to long-term survival and quality of life. In either case, these principles can enable us to move beyond the use of VADs simply to treat children with cardiogenic shock and bridge them to transplant. Rather, VADs are simply one option for the treatment of heart failure. The goal should always be to have each child live with her own heart if possible for as long as possible and as well as possible. Which treatment option we use, medicine, mechanical support, transplantation, should be guided by the interaction between the capabilities of each and the patient in front of us.

\section{References}

1. Kirklin JK, Naftel DC, Pagani FD, Kormos RL, Stevenson L, Miller M, et al. Long-term mechanical circulatory support (destination therapy): on track to 
compete with heart transplantation? J Thorac Cardiovasc Surg. 2012;144: 584-603.

2. Pinney SP, Anyanwu AC, Lala A, Teuteberg JJ, Uriel N, Mehra MR. Left ventricular assist devices for lifelong support. J Am Coll Cardiol. 2017;69:2845-61.

3. Adachi I. Pediatric ventricular assist device support as a permanent therapy: clinical reality. J Thorac Cardiovasc Surg. 2019;158:1438-41.
4. VanderPluym CJ, Adachi I, Niebler R, Griffiths E, Fynn-Thompson F, Chen S, et al. Outcomes of children supported with an intracorporeal continuous-flow left ventricular assist system. J Heart Lung Transplant. 2019;38:385-93.

5. Kormos RL, Cowger J, Pagani FD, Teuteberg JJ, Goldstein DJ, Jacobs JP, et al. The Society of Thoracic Surgeons intermacs database annual report: evolving indications, outcomes, and scientific partnerships. Ann Thorac Surg. 2019;107:341-53. 